\title{
LETTERS
}

\section{Recovery, Dependence or Death After Discharge}

\author{
Siamak Sabour, MD, PHD \\ Shahid Beheshti University of Medical Sciences, Department of Clinical Epidemiology, Tehran, Iran
}

$\mathrm{J}$ Gen Intern Med 28(3):342

DOI: $10.1007 / \mathrm{s} 11606-012-2311-2$

(C) Society of General Internal Medicine 2012

To the Editors:- I was interested to read the paper by Barnes and colleagues published online in JGIM on September 30, 2012. ${ }^{1}$ The authors aimed to develop a prognostic index to estimate one-year probabilities of recovery, dependence or death in older hospitalized patients who are discharged with incident activities of daily living (ADL) dependence. They retrospectively used a cohort data set, applying multinomial logistic regression to develop a prognostic index. The authors reported that key predictors of recovery, dependence or death were age, sex, number of instrumental activities of daily living (IADL) dependencies 2 weeks prior to admission, number of ADL dependencies at discharge, dementia, cancer, number of other chronic conditions, reason for admission, and creatinine levels. ${ }^{1}$ Why did the authors not validate their model by dividing their data into two and develop the model on one half and test it on the other? Or use other methods such as bootstrapping to test the reliability of their model? ${ }^{2-4}$

As the authors point out in their conclusion, their model may be useful in clinical settings to guide care discussions and inform decision-making related to posthospitalization care. Such a conclusion may lead to mismanagement of the patients, due to lack of validation of the prognostic model..$^{2-4}$ As a take home message, without validation of a prognostic model, generalizability should be avoided. ${ }^{2-4}$

Corresponding Author: Siamak Sabour, MD, PHD; Shahid Beheshti University of Medical Sciences, Department of Clinical Epidemiology, Chamran, Evin, Tehran, Iran (e-mail: s.sabour@sbmu.ac.ir).

\section{REFERENCES}

1. Barnes DE, Mehta KM, Boscardin WJ, Fortinsky RH, Palmer RM, Kirby KA, Landefeld CS. Prediction of recovery, dependence or death in elders who become disabled during hospitalization. J Gen Intern Med.. doi: 10.1007/s11606-012-2226-y. Epub ahead of print.

2. Jeckel JF, Katz DL, Elmore JG, Wild DMG. Epidemiology, Biostatistics and Preventive Medicine. 3rd ed. Philadelphia: Saunders, Elsevier; 2007.

3. Rothman JK, Greenland S, Lash TL. Modern Epidemiology. 3rd ed. Baltimore: Lippincott Williams \& Wilkins; 2008.

4. Szklo M, Nieto FJ. Epidemiology; Beyond the Basics. Manhattan: Jones and Bartlett Publisher; 2007. 